\title{
Dinâmica de aplicação de modelo de seleção tipográfica no contexto acadêmico
}

\author{
Dynamics of application of a typographic selection model in the \\ academic context
}

MEÜRER, Mary Vonni

Universidade Federal de Santa Catarina - UFSC I mary.meurer@ufsc.br

GONCALVES, Berenice Santos

Universidade Federal de Santa Catarina - UFSC I berenice@cce.ufsc.br

\begin{abstract}
Resumo
Este artigo descreve uma dinâmica de pesquisa que teve por objetivo avaliar um modelo de apoio ao processo de seleção tipográfica. A versão preliminar do modelo foi construída com base na revisão de literatura e consulta a especialistas e faz parte de um estudo mais amplo (MEÜRER, 2017). A fase da pesquisa aqui relatada, de abordagem qualitativa, foi estruturada em 3 principais momentos, a saber: preparo, aplicação da dinâmica e resultados. A dinâmica de aplicação do modelo ocorreu no contexto de desenvolvimento de projetos de conclusão do curso de Design que tinham como ênfase o design editorial. Ao longo de um semestre os acadêmicos adotaram o modelo para selecionar as fontes que foram usadas em seus projetos. O processo foi acompanhado pela pesquisadora e avaliado a partir de técnicas qualitativas. A partir dos resultados são discutidas contribuições e indicados aspectos para refinamento do modelo.
\end{abstract}

Palavras Chave: Seleção tipográfica. Pesquisa qualitativa. Dinâmica em contexto de projeto.

\section{Abstract}

This paper describes a research that aimed to evaluate a support model for the typographic selection process. The preliminary version of the model was constructed based on literature review and consultation with experts and is part of a larger study (MEÜRER, 2017). The part of the research reported herein uses a qualitative approach and was structured in 3 main phases, namely: preparation, application of the model, and results. The model was applied in the development of projects for the Design degree completion, specifically those with focus on editorial design. Over a semester, academics used the model to select the fonts to their projects. The process was monitored by the researcher and evaluated using qualitative techniques. From the results, we discuss contributions and indicate aspects for further refinement.

Keywords: Typographic selection. Qualitative research. Project context dynamics. 


\section{INTRODUC̣ÃO}

A aplicação da tipografia no contexto do design editorial envolve várias etapas, iniciando pela escolha dos tipos que serão usados no projeto, para depois definir os padrões de utilização - título, subtítulos, retrancas, legendas - a grade construtiva ou grid da página e a diagramação efetivamente, quando todo o texto é distribuído pelo documento de acordo com as regras pré-estabelecidas pelo designer. Todas estas etapas são fundamentais para garantir um resultado satisfatório no projeto editorial, ou seja, um material adequado às necessidades do leitor e do conteúdo. O designer precisa ter o devido cuidado com cada uma delas, pois como observa Bringhurst (2015, p. 28) "este é o começo, o meio e o fim da prática tipográfica: escolha e use os tipos com sensibilidade e inteligência".

Sem desconsiderar a importância das demais etapas do projeto editorial, este estudo tem como ênfase o início do processo, ou seja, quando o designer busca pelos tipos que serão usados no material, como mostra a figura 1.

Figura 1 - Aplicação da tipografia no contexto do design editorial.

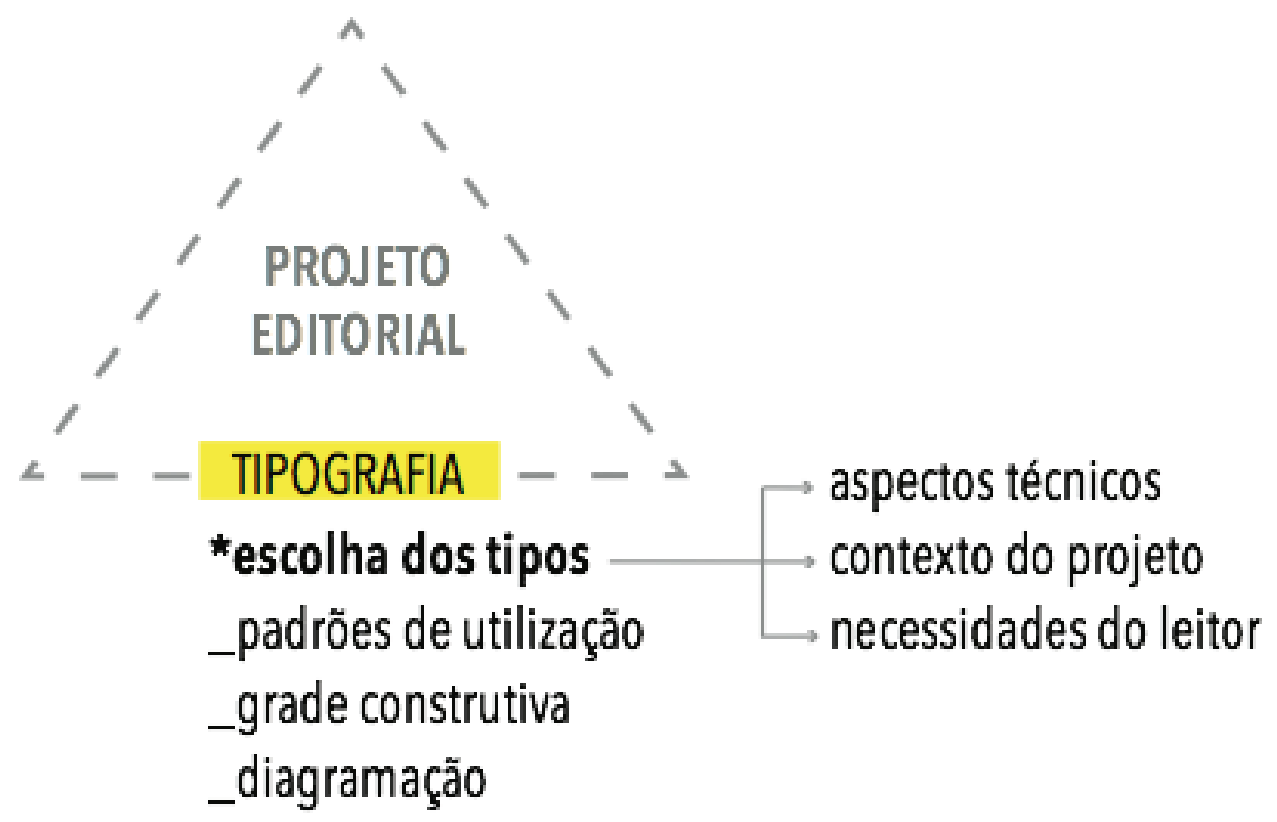

Fonte: as autoras.

Segundo Fuentes (2006 p. 73) "existem razões técnicas, razões estéticas, razões de código, e finalmente, mas não menos importantes, razões efetivas e de eficácia comunicativa" que devem ser consideradas ao fazer uma seleção tipográfica. Uma escolha precipitada e sem repertório pode resultar em problemas no desenvolvimento do projeto ao perceber, por exemplo, que a fonte 
escolhida não apresenta todos os caracteres necessários, dificulta a leitura ao ser impressa em determinado papel ou ainda, não foi eficiente na comunicação com o público pretendido.

Como escolher bem as fontes tipográficas para cada projeto? Segundo o guia Typography Primer (TYPOGRAPHY..., 2000) publicado pela Adobe ( diversos fatores, como público-alvo, valores estéticos, tom da mensagem e meio de publicação, influenciam na escolha do tipo. Para Ali (2009) as escolhas em tipografia são incertas e existem muitas incógnitas e variáveis que precisam ser trabalhadas. A autora afirma que é preciso um longo período de estudo e aplicação para se ter domínio sobre o assunto. Certamente, equacionar todos os aspectos envolvidos na seleção tipográfica não é uma tarefa fácil principalmente para estudantes ou profissionais em início de carreira. Segundo texto de Jury (apud HELLER, 2004), o elevado número de fontes tipográficas projetadas e distribuídas nos últimos anos constitui um desafio para os professores de projeto, que buscam estabelecer critérios e padrões para a boa tipografia. $O$ autor observa ainda que sente dificuldade em orientar os alunos na avaliação do que é "bom" e "mau", o que funciona e não funciona, diante de tantas experimentações tipográficas.

Como observa Bringhurst (2015), embora atualmente um designer possa ter acesso a milhares de fontes digitais por meio da internet, as suas seleções parecem sempre incompletas. Hendel (2003) e Chen e Choi (2006) concordam com Bringhurst ao afirmar que o grande número de fontes disponíveis atualmente dificulta a escolha. Hendel (2003) observa que a era digital permitiu que as fontes fossem produzidas com muito mais rapidez por eliminar as etapas de produção como matrizes, moldes e fundição. As fontes digitais tem um custo muito menor do que os tipos de metal, podendo ser adquiridas com muito mais variedade. Unger (2016) comenta ainda que os avanços tecnológicos ocorridos a partir da década de 1980 contribuíram para acelerar o processo de introdução de novas fontes no mercado em quantidades inéditas.

É evidente que a quantidade de fontes disponíveis, mais de dez mil famílias tipográficas cadastradas no site FontShop(C), apenas para citar um exemplo, não garante qualidade nem tampouco facilita o processo de seleção. Ao contrário, atualmente é preciso escolher entre muitas opções que são lançadas todos os dias, não só por profissionais, mas também por amadores. Chen e Choi (2006) alertam para a dificuldade em encontrar as fontes nos catálogos que geralmente estão organizados em categorias, o que requer do designer conhecimentos prévios sobre terminologia tipográfica. Além disso, se antes era preciso apenas definir qual o estilo tipográfico mais adequado para a publicação e depois escolher entre 3 ou 4 tipos de acordo com este estilo, agora, por exemplo, ao decidir por um tipo geométrico o designer precisará considerar um conjunto de opções que vai muito além da Century Gothic e da Futura. Para Henestrosa, Meseguer e Scaglione (2014) muitos fatores pessoais interferem 
neste processo de seleção tipográfica, influenciando os profissionais na escolha de um tipo em relação ao outro, gerando sempre resultados diferentes, mesmo que para contextos semelhantes. "No entanto, os profissionais terão mais chances de alcançar um bom resultado se buscarem respostas fundamentadas, ao invés de seguir escolhas caprichosas." (HENESTROSA; MESEGUER; SCAGLIONE, 2014, p. 20).

Com o objetivo de apoiar o processo de seleção tipográfica para projetos editoriais, facilitando o processo de tomada de decisão, foram desenvolvidos 8 critérios de seleção que constituíram um modelo publicado na tese "Seleção Tipográfica no Contexto do Design Editorial: Um Modelo de Apoio à Tomada de Decisão" (MEÜRER, 2017). A abordagem metodológica da referente pesquisa foi composta por 4 fases: revisão de literatura, construção do modelo preliminar, aplicação do modelo preliminar no contexto de projeto e modelo de apoio à seleção tipográfica.

O presente artigo trata da terceira fase da pesquisa de doutorado, constituída de uma dinâmica de aplicação da versão preliminar do modelo, identificado como MAST - Modelo de Apoio à Seleção Tipográfica. Nesta dinâmica alunos em fase de conclusão do curso de Design aplicaram o modelo para selecionar as fontes a serem usadas em projetos de design editorial. Posteriormente relataram por meio de questionário e entrevista sua experiência com o modelo. Os procedimentos e os resultados obtidos são detalhados neste artigo.

\section{PROCEDIMENTOS DA DINÂMICA DE APLICAC̣ÃO DO MODELO}

Seguindo as recomendações de Creswell (2010), Prodanov e Freitas (2013) foi definida a sequência de procedimentos apresentada na figura 2. Esta sequência foi dividida em 3 procedimentos à saber: preparo, aplicação e resultados e discussões.

O preparo envolveu a seleção e contato com os participantes, a aprovação do projeto de pesquisa junto ao comitê de ética' e a organização dos documentos necessários. Sobre o material complementar, este foi desenvolvido a partir do conteúdo resultante da revisão de literatura, mas com algumas adaptações na redação para que o texto ficasse mais direto e atrativo para o público.

1 Segundo Prodanov e Freitas (2013), a Resolução CNS 196 (1996) define Comitês de Ética em Pesquisa - CEPs - como colegiados públicos que atuam de forma interdisciplinar e independente e foram criados para defender os interesses dos participantes em pesquisas, mantendo assim os padrões éticos. 
Figura 2 - Sequência de procedimentos da dinâmica de aplicação do modelo.

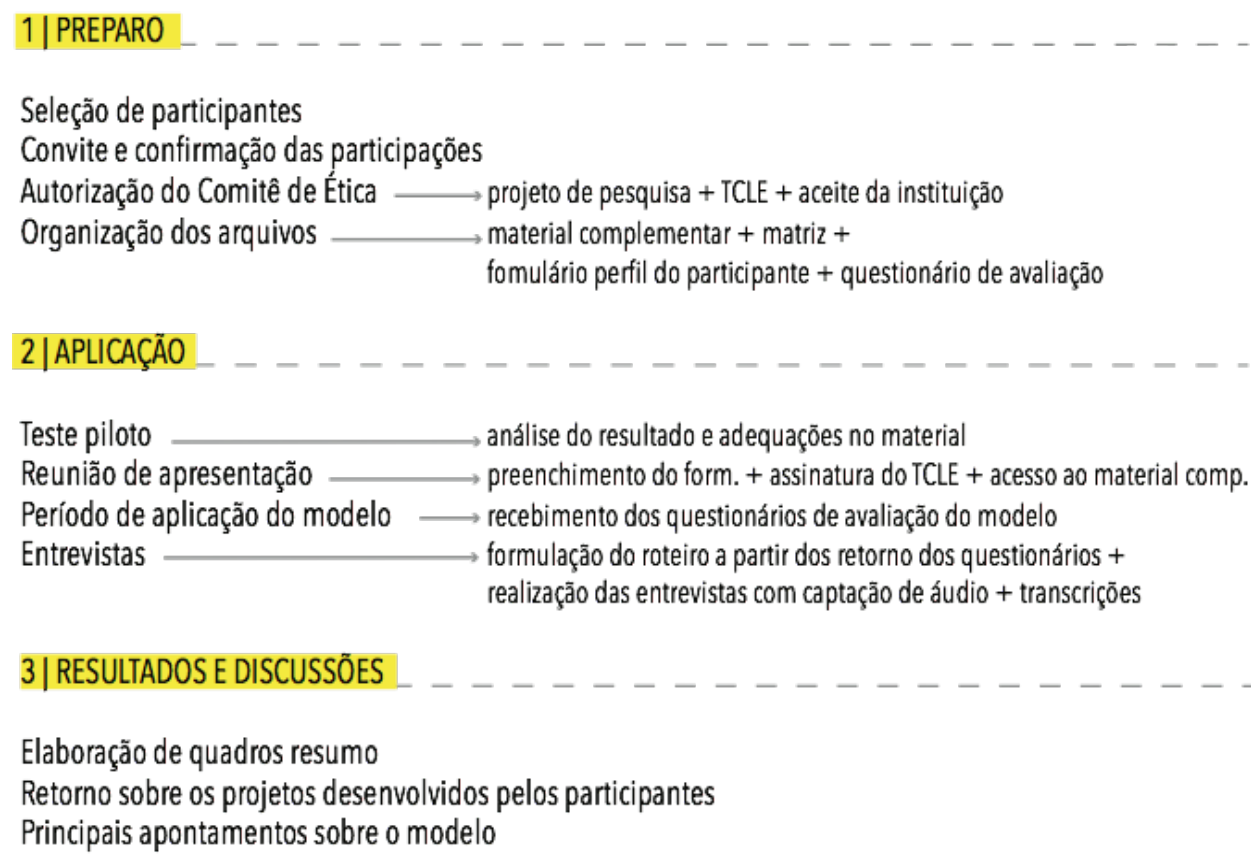

Fonte: As autoras.

A etapa de aplicação, correspondeu à dinâmica no contexto de projeto. Esta etapa contemplou a realização de um teste piloto, posteriormente uma reunião de apresentação do modelo e da pesquisa para os participantes, preenchimento de questionário sobre o uso do modelo e por fim as entrevistas individuais.

Os procedimentos finais compreendem os resultados e discussões, que contemplam a elaboração de quadros resumo para comparar as informações obtidas em cada uma das entrevistas, além da seleção dos comentários mais pertinentes feitos pelos entrevistados. Neste momento também foi solicitado aos participantes, que após a finalização dos seus projetos, enviassem um comentário sobre os resultados obtidos enfatizando o uso das fontes selecionadas e algumas imagens dos livros, catálogos e cartilhas desenvolvidos para ilustrar estes resultados. Por fim, foi realizada uma análise geral para identificar os principais apontamentos sobre o modelo, incluindo a matriz e o material de apoio, buscando relacionar as correções necessárias.

\section{RESULTADOS DA DINÂMICA DE APLICAC̣ÃO DO MODELO}

Neste tópico será relatado todo o processo de realização da dinâmica para maior compreensão das suas particularidades, adequações e resultados. 


\subsection{Etapa de Aplicação}

O teste piloto deu início à etapa de aplicação e buscou simular a dinâmica que seria realizada com o grupo. Desta forma foram apresentados todos os documentos que seriam entregues aos demais participantes e também houve uma apresentação da pesquisa. Apenas em dois pontos foi preciso abreviar o processo de aplicação no teste piloto, a fim de garantir um retorno com tempo hábil para eventuais alterações antes de iniciar a dinâmica com o restante do grupo, o que deveria ocorrer no início de setembro de acordo com o cronograma da pesquisa. Desta forma, foi solicitado à aluna que participou do teste que desse um retorno sobre o uso do modelo no prazo de 7 dias após a apresentação e com isso, diante deste prazo não foi possível que ela usasse o modelo efetivamente para a seleção tipográfica do seu projeto, visto que o briefing não estava completamente definido. A aluna fez então uma pré-seleção, que foi refeita posteriormente com a definição do briefing. Porém não considerou-se que este fato tenha impactado na avaliação do modelo pela aluna.

Sobre o retorno dado por ela ao final do processo, a mesma relatou que não encontrou dificuldades em preencher o formulário de dados do participante, compreender o modelo, a matriz e o material complementar, nem tampouco em preencher o questionário final. Sugeriu apenas que o material complementar trouxesse mais informações sobre questões como ink trap e algarismos antigos, pois precisou consultar outras referências para compreender melhor estes termos que considerou importantes para o seu projeto.

Realizado o teste piloto, onde não foi constatada a necessidade de alterações emergenciais nos documentos ou no modelo e seus complementos, definiu-se que era viável dar sequência à fase de aplicação. Desta forma, no dia 30 de agosto de 2016 aconteceu a reunião de apresentação da pesquisa e do modelo para os outros 5 participantes convidados. Inicialmente houve a tentativa de escolher uma data onde todos pudessem estar presentes, porém devido aos compromissos dos participantes e da pesquisadora isto não foi possível. Como uma das participantes não residia em Florianópolis, vindo para a universidade apenas em datas muito específicas, foi preciso que no dia da apresentação esta aluna participasse à distância, usando a ferramenta Google Hangout $($. Mas, assim como os demais, ela recebeu todos os documentos via e-mail e entregou o TCLE e o formulário de dados do participante devidamente preenchidos e assinados na mesma semana.

Após uma breve apresentação da pesquisa foi solicitado aos participantes que lessem o TCLE e preenchessem o formulário com seus dados. Depois foi entregue o modelo preliminar impresso com o link para acesso ao material complementar, a matriz e ao questionário, conforme mostra a figura 3. 
Figura 3 - Versão preliminar do modelo utilizada na dinâmica de aplicação.

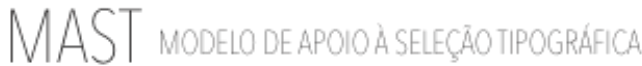

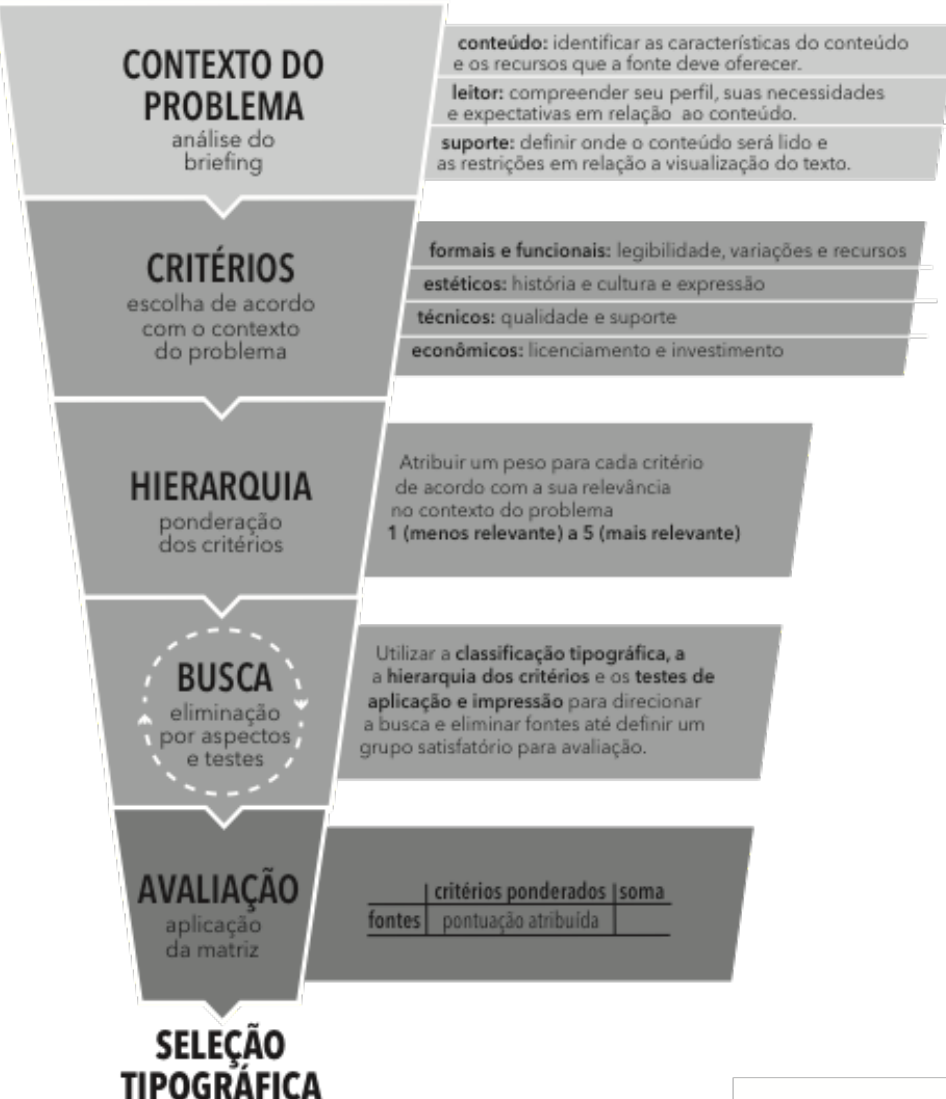

TIPOGRAFICA

Para melhor compreensão das etapas do modelo e seus critérios utilize o Material Complementar disponivel neste link: https://goo.gl/M37jNY

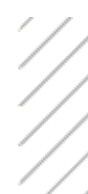

MAST - Modelo de Apoio à Seleçăo Tipográfica está sendo desenvolvido pela Prof' Mary Meürer em sua tese de doutorado no PósDesign da UFSC 0 modelo năo pode ser reproduzido, alterado ou comercializado. Dúvidas: mary.meurer@ufsc.br

Fonte: Meürer (2017).

A versão preliminar do modelo desenvolvido, do tipo conceitoprocessual ${ }^{2}$, orientava o processo de tomada de decisão em cinco etapas, a saber: contexto do problema, critérios, hierarquia, busca e avaliação. A partir da análise do contexto, o modelo indicava a ponderação dos 8 critérios de seleção: legibilidade, variações e recursos, aspectos histórico-culturais, expressão,

2

Segundo Harrison e Treagust (2000), modelos conceito-processuais são usados pelos professores para explicar processos imateriais para os estudantes, que em geral pensam em termos concretos. Consistem nos modelos mais complexos e abstratos entre os demais modelos analógicos.

Projética, Londrina, v.9, n.2 supl. p. 125-142, nov. 2018 
qualidade, suporte, licenciamento e investimento. De acordo com este contexto, o aluno deveria definir os pesos ou optar pela eliminação de critérios. O modelo orientava, ainda, sobre o processo de busca e avaliação das fontes por meio de uma matriz de seleção.

Sobre o material complementar, além do conteúdo textual, também foram incluídas imagens e links para ferramentas online que poderiam auxiliar o aluno no desenvolvimento das etapas, principalmente a de busca. O material foi desenvolvido no software editorial Adobe InDesign e disponibilizado em formato Adobe PDF para os participantes. Da mesma forma a matriz também foi fornecida em arquivo do software Microsoft Excell. A figura 4 mostra algumas páginas do material complementar para exemplificá-lo.

Figura 4 - Exemplos de páginas da versão preliminar do material complementar.
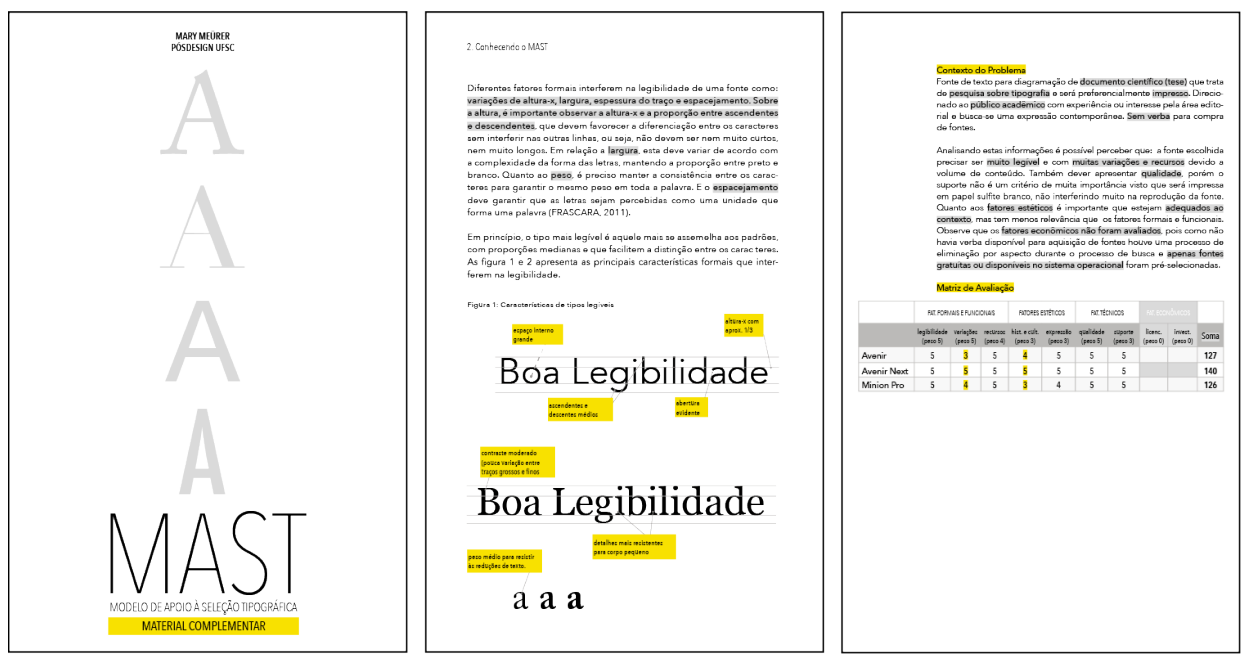

Fonte: As autoras.

Durante o período de aplicação do modelo os participantes mantiveram contato com a pesquisadora via e-mail para sanar algumas dúvidas sobre o processo da dinâmica de projeto, sendo que as mais frequentes foram em relação a atribuição dos pesos aos critérios e a avaliação de cada fonte na matriz.

\subsubsection{Questionários sobre a dinâmica de aplicação do modelo}

Conforme solicitado na reunião de apresentação, assim que foram finalizando a aplicação do modelo na seleção das fontes para os seus projetos os participantes enviaram os questionários respondidos. A partir dos questionários foi elaborado um quadro síntese dividido de acordo com os principais temas abordados: a clareza do modelo, a relevância do material complementar, 
o conteúdo e a organização do material complementar, a organização e a funcionalidade do arquivo da matriz e ainda observações gerais de acordo com a demanda dos entrevistados. O quadro 1 exemplifica a síntese.

Quadro 1 - Exemplo da síntese dos resultados dos questionários enviados pelos participantes.

\begin{tabular}{lll}
\hline & Participante 1 & ...Participante 5 \\
\hline O material & Sim, pois a introdução & Observou que o material auxiliou \\
complementar & contribuiu para relembrar & na revisão de alguns conceitos \\
foi fundamental para o & questões relacionadas a & relacionados a tipografia que \\
entendimento do MAST? & tipografia. Observou também & são essenciais para a seleção \\
& que a síntese dos critérios & tipográfica.Afirmou ainda que \\
& e os exemplos no final do & durante a aplicação da matriz \\
& material auxiliaram a parte & voltou ao material algumas vezes \\
& prática. & para ter mais segurança ao definir \\
& & os pesos. \\
\hline
\end{tabular}

Fonte: As autoras.

No intervalo de 18 de setembro a 27 de outubro de 2016, a medida em que os questionários eram recebidos e analisados, os protocolos das entrevistas eram preparados com base nas informações obtidas. A análise prévia dos questionários e dos formulários preenchidos pelos participantes permitiu que a pesquisadora conhecesse melhor os entrevistados e suas percepções sobre o MAST, conforme recomendam Prodanov e Freitas (2013). O quadro 2 exemplifica esta relação entre os itens do questionário e do protocolo.

Quadro 2 - Exemplo da síntese dos resultados dos questionários enviados pelos participantes.

\begin{tabular}{l|l}
\hline Documento & Perguntas e respostas \\
\hline pergunta no questionário & O MAST está claro pra você? \\
\hline resposta no questionário & $\begin{array}{l}\text { A proposta e os conceitos sim, porém acredito que os } \\
\text { critérios de avaliação ainda são muito subjetivos e "soltos", } \\
\text { tive um pouco de dificuldades em atribuir notas a algumas } \\
\text { fontes em certos critérios. }\end{array}$ \\
\hline $\begin{array}{l}\text { pergunta gerada para o } \\
\text { protocolo de entrevista }\end{array}$ & $\begin{array}{l}\text { Comente a dificuldade de atribuir notas para os critérios de } \\
\text { avaliação e a subjetividade percebida no modelo, de acordo } \\
\text { com o que foi citado no questionário. }\end{array}$ \\
\hline
\end{tabular}

Fonte: As autoras.

Como mostra o quadro 2, a insatisfação manifestada pelo participante no questionário resultou em uma pergunta no protocolo de entrevista com o objetivo de compreender melhor a dificuldade mencionada. Da mesma forma todas as outras respostas dadas nos questionários foram consideradas ao definir os protocolos de entrevista.

Paralelamente ao processo de definição do protocolo de entrevista foram organizados os procedimentos para a realização das mesmas. Como ambiente foi selecionado o Hiperlab, laboratório do curso de Design que conta em sua estrutura com uma sala reservada para as entrevistas, possibilitando que 
estas ocorressem de forma privativa, sem interrupções. O fato do laboratório se localizar na própria universidade facilitou o acesso dos alunos. As datas e horários foram marcados previamente de acordo com a disponibilidade de cada um e as entrevistas aconteceram na primeira semana de novembro em horários alternados, com duração de aproximadamente 30 minutos cada, embora tenha sido reservada 1 hora para cada uma. Considera-se que a otimização do tempo foi uma consequência do preparo prévio do protocolo com base no questionário e no formulário.

Conforme mencionado anteriormente o áudio das entrevistas foi gravado e transcrito posteriormente. A pesquisadora não realizou anotações durante as entrevistas, podendo desta forma direcionar toda sua atenção para o diálogo estabelecido com cada um dos entrevistados. Manteve-se durante todo o processo uma abordagem cordial, buscando sempre deixar os entrevistados à vontade para fazer críticas e sugestões sobre o modelo. Considera-se que esta fase transcorreu de forma satisfatória, sem maiores implicações e que os participantes trouxeram contribuições muito relevantes.

Para o processo de análise das entrevistas foram seguidas as recomendações de Creswell (2010). O primeiro passo indicado pelo autor inicia com as transcrições e a organização de todo o material obtido durante as entrevistas, ou seja digitalização de documentos, anotações, separação dos dados de acordo com as fontes de informação entre outras ações necessárias antes de iniciar a análise. Segundo Creswell (2010) este é o primeiro passo a ser seguido. O segundo passo corresponde a leitura dos dados para uma interpretação geral das informações, buscando identificar semelhanças entre as opiniões dos entrevistados. Como terceiro passo o autor sugere que seja feita a codificação, que corresponde a organização e categorização das informações de acordo com os termos usados pelos próprios participantes, se possível. O quarto passo sugerido por Creswell (2010) corresponde a gerar uma descrição dos locais, das pessoas ou dos temas abordados. Estes temas apontam os principais resultados e podem ser usados como títulos para as seções de resultados do estudo. O quinto passo contempla uma narrativa qualitativa, onde os resultados da análise são discutidos de forma detalhada, tema a tema, ou interconectada. Por fim, no sexto passo, Creswell (2010) sugere que o pesquisador apresente os seus argumentos em relação aos resultados, comparando-os com o seu próprio repertório ou com a revisão de literatura. O tópico a seguir apresenta os resultados das entrevistas após o processo de análise.

\subsection{Etapa de resultados e discussões referentes à dinâmica}

Após a transcrição das entrevistas foram selecionados os trechos mais significativos para organizar um quadro que pudesse sintetizar a opinião dos participantes. O quadro foi organizado de acordo com os principais temas 
abordados que envolvem o contexto da aplicação, o modelo, o material complementar, a matriz e observações complementares. As respostas foram organizadas de acordo com a relação com estes temas para facilitar a comparação entre a percepção dos participantes. A seguir estão comentadas as constatações da pesquisadora a partir das informações obtidas nas entrevistas.

Todos os protocolos de entrevista iniciavam com perguntas relacionadas ao contexto de aplicação do modelo, ou da pesquisa propriamente. O objetivo era saber se o cronograma da pesquisa foi compatível com o dos projetos e se o processo de seleção se adequou às necessidades dos participantes. Sobre esta questão todos foram unânimes ao afirmar que sim, que a apresentação do modelo bem como o prazo para aplicá-lo ocorreram no momento certo, quando estavam para iniciar a seleção das fontes para os seus projetos. Também comentaram que o acesso ao material da pesquisa facilitou o desenvolvimento dos seus projetos, pois não tinham até o momento o conteúdo sobre tipografia e teriam que buscar por referências. O comentário da participante 4 sintetiza esta afirmação.

Pra mim ele se encaixou bem no desenvolvimento do projeto, achei que facilitou muito o meu trabalho porque ele basicamente reuniu tudo que eu já iria ter que pesquisar dentro do próprio material. E não atrapalhou em nada porque chegou no momento certo (PARTICIPANTE 4).

Considera-se que a adequação ao cronograma e a relevância do conteúdo para o desenvolvimento dos projetos colaboraram para que os participantes se envolvessem efetivamente com a pesquisa, demonstrando comprometimento e interesse pela mesma.

Seguindo o protocolo de entrevista teve início o questionamento sobre o modelo para verificar se a estrutura e a representação do mesmo foi compreendida facilmente pelos participantes. Também sobre essa questão houve concordância entre os entrevistados pois todos declararam ter compreendido o modelo.

Observou-se que os participantes comentavam com mais propriedade o material complementar e a matriz, chegando a confundir os termos. Ao serem indagados sobre o modelo, inicialmente respondiam sobre o material complementar ou sobre a matriz e só depois que a entrevistadora se referia de forma mais detalhada, lembrando sobre a figura com etapas é que eles compreendiam. Atribui-se esta confusão ao fato do modelo não ser um arquivo separado, como a matriz e o material de apoio, que foram mais efetivamente utilizados pelos entrevistados. Outro ponto é que na capa do material complementar o nome MAST está em maior destaque e em letras menores o termo material complementar. De qualquer forma, após breve exemplificação, todos compreenderam a diferença e passaram a se referir da forma correta. 
Após comentarem sobre o modelo os entrevistados foram instigados a falar sobre o material complementar, se a organização estava adequada, se o conteúdo era apropriado ou o que mais quisessem comentar. Em relação ao conteúdo, embora tenham sido sugeridas algumas mudanças, de uma forma geral os participantes consideraram o conteúdo adequado. Já haviam registrado isso nos questionários, observando inclusive que as referências e os links para ferramentas online contribuíram para o processo de seleção. Porém, o participante 3 considerou que o conteúdo sobre avaliação das fontes na matriz deveria trazer mais exemplos sobre pontuação.

Achei o material bem claro, foi bem fácil de usar, tirando essa parte da subjetividade das notas, o que vale 1 o que vale 2 , pra mim foi bem fácil de usar. A única consideração que eu fiz no questionário foi que poderia ter mais exemplos com outras fontes (PARTICIPANTE 3).

Embora o material complementar tenha um tópico dedicado a explicar o processo de avaliação das fontes, a atribuição de notas não está devidamente detalhada, tendo maior ênfase a explicação sobre contexto de projeto e peso dos critérios.

Sobre a organização do conteúdo, não houveram críticas, todos consideraram adequada a sequência das informações. Cabe reforçar que o conteúdo do material complementar segue a mesma ordem das etapas do modelo e a descrição dos critérios acompanha a sequência em que estes aparecem na matriz.

Outro ponto unânime nas observações dos participantes foi o quadro que apresenta a síntese dos critérios e ao qual alguns se referiram como tabela. Todos afirmaram ter consultado muito este quadro e que o mesmo os auxiliou durante a avaliação das fontes. Porém concordaram que se tivessem acesso apenas ao quadro, sem o conteúdo do material complementar, não seria suficiente para compreenderem os critérios e o processo de seleção. O comentário da participante 5 representa bem a opinião de todos.

Aquela tabela que tem a pergunta e as características, foi o que ajudou bastante na hora de pesquisa, quando eu estava avaliando. Mas acho que ela é enxuta demais para usar sozinha, a leitura foi bem importante, ai depois de tudo que já tinha lido a consulta rápida é que foi pela tabela (PARTICIPANTE 5).

Ainda sobre o quadro síntese dos critérios, o participante 3 fez uma sugestão sobre a sua posição no material complementar. $\mathrm{Na}$ sequência apresentada o modelo aparece no início e o quadro síntese quase no final, depois que são apresentados os critérios. O aluno sugeriu que o modelo e o quadro estivessem juntos, para facilitar a consulta simultânea. 
Sobre a apresentação do material complementar como um todo, também houveram sugestões para facilitar a sua utilização. O participante 3 sugeriu que a visualização deveria ser na horizontal, por ser mais adequada à tela. A participante 4 comentou que a abertura do material em tela cheia Ihe desagradou pois atrapalha a navegação entre os outros arquivos. Também pensando em uma melhor navegação e na interatividade entre os arquivos do material complementar e da matriz, a participante 5 sugeriu que os arquivos do material e da matriz estivessem integrados em uma página web ou outro recurso que facilitasse a navegação.

Em relação a funcionalidade da matriz, houve a sugestão da participante 5 de que ao passar o mouse sobre os critérios abrisse uma caixa com a descrição dos mesmos, conforme consta no material complementar, facilitando assim o entendimento destes critérios no momento da avaliação. Em relação ao arquivo da matriz, que foi produzida em uma planilha do Microsoft Excell, todos os participantes confirmaram não ter tido dificuldade ou encontrado algum erro ao utilizar, mesmo os que não estavam familiarizados com o software. A única ressalva foi feita pelo participante 3 , que relatou ter tido dificuldade em definir quantas fontes deveria colocar na matriz, visto que não encontrou um número definido no material.

Outro questionamento feito aos entrevistados foi sobre a avaliação, se encontraram dificuldades e como procederam. Um primeiro ponto a destacar refere-se a dificuldade em atribuir notas para as fontes, de acordo com os critérios. Para o participante 3 e para as participantes 4 e 5 foi mais difícil estabelecer a pontuação.

O participante 3 já havia comentado esta dificuldade ao mencionar que sentiu falta de mais exemplos sobre a pontuação das fontes, chegou inclusive a solicitar ajuda sobre este processo durante a aplicação do modelo pois sentiase inseguro em atribuir notas a cada fonte. Sobre esta questão, a participante 1 relatou que usou uma folha de papel para registrar suas observações ao definir a pontuação de cada fonte.

Em relação a busca pelas fontes que fariam parte da seleção, relatos feitos pelo participante 3 e pelas participantes 4 e 5, demonstraram que a etapa de eliminação por aspectos não estava bem clara no material pois não foi devidamente compreendida por eles inicialmente. 0 participante 3, por exemplo, comentou que embora precisasse de fontes com caracteres de fração, não estabeleceu este como um aspecto eliminatório. Desta forma, só depois de iniciar a avaliação na matriz, percebeu que apenas 3 fontes pré-selecionadas ofereciam este recurso que era imprescindível. Precisou então refazer a busca, atendo-se a este ponto.

Quanto a participante 5, seu comentário demonstrou dificuldade em compreender que no caso do investimento, quando não há verba para compra 
de fontes, este critério deve ser considerado eliminatório. Ou seja, apenas fontes gratuitas devem ser analisadas, portanto o critério investimento não precisa ser considerado, e ao invés de peso 5, passa a ter peso 0.

A participante 4 não enfatizou sua dúvida sobre a eliminação por aspectos na entrevista, mas havia comentado isso anteriormente quando pediu ajuda durante a aplicação do modelo. Na ocasião ela disse não ter compreendido se a legibilidade deveria ser um critério com peso máximo ou deveria ser um aspecto eliminatório. Embora as demais participantes não tenham feito comentários sobre este assunto, certamente a dificuldade de 3 pessoas aponta para a necessidade de maior esclarecimento sobre o mesmo no material complementar e no próprio modelo.

Ao final da entrevista foi perguntado aos participantes se após concluírem a etapa de aplicação do modelo notaram alguma mudança nas suas percepções em relação a tipografia no contexto do design editorial. A participante 1 destacou uma mudança na sua percepção em relação aos fatores estéticos e também a experiência de atribuir notas às fontes. Outro relato interessante foi da participante 2 , a mesma comentou que embora não utilizasse a matriz em seu estágio devido ao curto prazo de execução dos projetos, depois de ter participado da pesquisa passou a procurar as fontes de outra forma.

O relato destas participantes, aliado ao comentário da participante 5 que afirmou ter passado a prestar mais atenção aos detalhes das fontes, reforçam a relevância desta pesquisa. Confirma-se, portanto, a capacidade do modelo de apoiar o processo de seleção, oferecendo subsídios para que o aluno, ou outro usuário, consiga escolher as fontes para os seus projetos com mais critério.

Como as entrevistas foram realizadas durante o semestre, enquanto os PCCs estavam em desenvolvimento, os participantes ainda não haviam aplicado as fontes selecionadas de forma efetiva em seus projetos. Com o propósito de confirmar se as fontes selecionadas teriam atingido bons resultados ao serem aplicadas, no final do semestre foi enviado um e-mail aos participantes questionando sobre o desfecho dos projetos. Os comentários recebidos foram muito positivos e enfatizaram a eficiência do modelo preliminar. Alguns participantes enviaram imagens dos projetos concluídos para exemplificar a aplicação das fontes.

\section{CONTRIBUIC̣̃̃ES DA DINÂMICA DE APLICAC̣ÃO DO MODELO}

Para sintetizar as sugestões foi elaborado o quadro 3, com os aspectos positivos e negativos extraídos dos questionários e das entrevistas, onde é possível perceber que os aspectos positivos se sobressaem aos negativos, 
embora, estes não possam ser ignorados. Da mesma forma as sugestões foram consideradas para o aprimoramento do modelo.

Quadro 3 - Síntese do resultado da dinâmica de aplicação do modelo preliminar.

\begin{tabular}{l|l|l}
\hline Aspectos POSITIVOS & Aspectos NEGATIVOS & SUGESTÕES \\
\hline $\begin{array}{l}\text { Representação do modelo } \\
\begin{array}{l}\text { Conteúdo e organização do } \\
\text { material complementar; }\end{array}\end{array}$ & $\begin{array}{l}\text { Faltam mais exemplos sobre } \\
\text { o processo de avaliação das } \\
\text { fontes; }\end{array}$ & $\begin{array}{l}\text { A navegação entre o material } \\
\text { complementar e a matriz } \\
\text { mais integrada e interativa; }\end{array}$ \\
$\begin{array}{l}\text { Quadro síntese dos critérios } \\
\text { faita a consulta; }\end{array}$ & $\begin{array}{l}\text { Orientação sobre quantas } \\
\text { fontes devem ser avaliadas } \\
\text { nancionalidade do arquivo da }\end{array}$ & $\begin{array}{l}\text { Diagramar o material } \\
\text { complementar na horizontal } \\
\text { para melhor visualização na } \\
\text { tela; }\end{array}$ \\
$\begin{array}{l}\text { Atribuição de notas diminui a } \\
\text { subjetividade da seleção; }\end{array}$ & $\begin{array}{l}\text { Mais clareza na etapa de } \\
\text { eliminação por aspectos; }\end{array}$ & $\begin{array}{l}\text { Abertura em tela cheia do } \\
\text { material complementar } \\
\text { As fontes selecionadas foram }\end{array}$ \\
$\begin{array}{l}\text { satisfatórias para os projetos; } \\
\text { incomoda; }\end{array}$ & $\begin{array}{l}\text { Colocar o quadro síntese dos } \\
\text { critérios junto ao modelo no } \\
\text { material complementar. }\end{array}$ \\
$\begin{array}{l}\text { dos participantes sobre a } \\
\text { design editorial. }\end{array}$ & $\begin{array}{l}\text { Necessita de revisão no } \\
\text { material pois apresenta erros } \\
\text { de digitação. }\end{array}$ & \\
\hline
\end{tabular}

Fonte: As autoras.

Ao final do processo de aplicação da versão preliminar do modelo constatou-se que ele atendeu ao objetivo proposto, apoiando o processo de seleção tipográfica para projetos de design editorial. Tanto o modelo, quanto o material complementar e a matriz de avaliação ainda necessitavam de ajustes e reformulações conforme apontado pelos participantes, mas segundo os mesmos, são mudanças para um aprimoramento do conjunto e que não comprometeram sua eficácia.

É importante destacar que nas entrevistas também foi possível perceber a mudança de percepção dos participantes em relação a tipografia aplicada ao design editorial. Com isso atingiu-se uma expectativa das pesquisadoras, a de que após usar o modelo as pessoas ampliem seu repertório em relação aos tipos e passem a observar com mais cuidado as características tipográficas que podem interferir no resultado final dos projetos. Por exemplo, preocupar-se em conferir se a fonte oferece todos os recursos necessários, se o custo das licenças é compatível com o orçamento do projeto, se o estilo tipográfico está adequado ao conteúdo e ao público, entre outros fatores apontados pelo modelo e seus critérios. De acordo com o depoimento da participante 2, talvez na rotina do mercado não seja possível seguir todas as etapas do modelo detalhadamente, mas a seleção não será feita de forma aleatória ou subjetiva.

Em relação aos aspectos negativos constatados após a aplicação do modelo, considera-se que se referem principalmente a apresentação e a falta de interatividade entre as partes: o material complementar, o modelo propriamente e a matriz. As informações precisam estar mais integradas e detalhadas, facilitando a relação entre elas. 
A dificuldade mais comentada pelos participantes foi referente ao entendimento do processo de eliminação por aspectos, que embora esteja explicado no material e indicado no modelo, talvez não tenha tido o devido destaque dada a sua importância para um processo de seleção adequado. Como forma de melhorar esta questão optou-se por alterar o termo de eliminação por aspectos, indicado na literatura (STERNBERG, 2010), para critério eliminatório, estabelecendo assim maior relação com a importância do critério para o contexto do projeto.

Outra questão que precisou ser melhor esclarecida, ou exemplificada, foi a avaliação propriamente. Sobre esta questão, constatou-se portanto, que embora a avaliação utilizando a matriz pretenda tornar o processo mais objetivo, pode permanecer certa subjetividade e insegurança no momento de atribuir a pontuação a cada fonte em cada critério. Acrescentar mais exemplos ao material poderia facilitar o processo de avaliação, segundo o participante 3 .

\section{CONSIDERAC̣õES FINAIS}

Sobre os critérios que compõe o modelo, considera-se que a dinâmica com os alunos confirmou sua adequação, pois não houve nenhuma sugestão dos participantes em relação à necessidade de alteração destes critérios.

Quanto ao processo de seleção tipográfica como um todo, o relato dos participantes reforçou o que já havia sido indicado nas fases anteriores da pesquisa. Os alunos que participaram da pesquisa relataram que há uma dificuldade em selecionar fontes para os projetos, muitas vezes tomando decisões pautadas em preferências pessoais. Importante destacar que o recurso de usar perguntas para orientar a seleção (HASLAM, 2007; FONTOURA; FUKUSHIMA, 2012; PAMENTAL, 2014), que gerou o quadro com perguntas orientadoras para a seleção tipográfica, foi indicado por todos os participantes como muito útil no processo de avaliação das fontes, sendo repetidamente consultado. Foi sugerido inclusive que este quadro ficasse próximo ao modelo, facilitando a consulta simultânea.

Considera-se que a dinâmica de aplicação do modelo enriqueceu a pesquisa, principalmente devido as contribuições geradas a partir das entrevistas individuais. Desta forma os alunos puderam relatar com mais detalhes o que já haviam manifestado por meio de questionário, trazendo dúvidas e sugestões muito pertinentes. Acrescenta-se o fato destes alunos estarem desenvolvendo seus projetos de conclusão de curso, compartilhando no final do semestre os resultados obtidos e manifestando seu grau de satisfação com as fontes escolhidas após o uso das mesmas. A dinâmica de aplicação foi além de uma 
simulação de uso do modelo em projetos fictícios, houve um contexto real e o uso efetivo das fontes selecionadas, confirmando que o modelo foi relevante no apoio ao processo de seleção tipográfica.

Por fim, é importante reforçar que foi apresentada neste artigo uma versão preliminar do modelo e que após a realização da dinâmica foram realizadas adequações no mesmo. A versão final do modelo, da matriz e do material complementar deve ser consultada na tese. (MEÜRER, 2017). 


\section{REFERÊNCIAS}

ALI, Fatima. A arte de editar revistas. São Paulo: Ed. Nacional, 2009.

BRINGHURST, Robert. Elementos do estilo tipográfico. São Paulo: Cosac Naify, 2015.

CHEN, Hsin-Liang; CHOI, Gilok. An online font library: evaluation by graphic design students. The Electronic Library, Texas, v. 24, n. 6, p. 774-790, 2006.

CRESWELL, John W. Projeto de pesquisa: métodos qualitativo, quantitativo e misto. 3. ed. Porto Alegre: Artmed, 2010.

FONTOURA, Antônio Martiniano; FUKUSHIMA, Naotake. Vade-mécum de tipografia. Curitiba: Insight, 2012.

FUENTES, Rodolfo. A prática do design gráfico: uma metodologia criativa. São Paulo: Edições Rosari, 2006.

HASLAM, Andrew. O livro e o designer Il: como criar e produzir livros. São Paulo: Rosari, 2007.

HELLER, Steven. The education of a typographer. Nova York: Allworth Press, 2004.

HENDEL, Richard. O design do livro. São Paulo: Ateliê, 2003.

HENESTROSA, Cristobal; MESEGUER, Laura; SCAGLIONE, José. Como criar tipos: do esboço à tela. Brasília: Estereográfica, 2014.

MEÜRER, Mary Vonni. Seleção tipográfica no contexto do design editorial: um modelo de apoio à tomada de decisão. 2017. Tese (Doutorado em Design) Universidade Federal de Santa Catarina, Centro de Comunicação e Expressão, Florianópolis, 2017.

PAMENTAL, Jason. Responsive typography: using type well on the web. Sebastopol: O'Reilly Media, 2014.

PRODANOV, Cleber Cristiano; FREITAS, Eernani Cesar. Metodologia do trabalho científico: métodos e técnicas da pesquisa e do trabalho acadêmico. Novo Hamburgo: Feevale, 2013. Disponível em: <http://www.feevale.br/ Comum/midias/8807f05a-14d0-4d5b-blad-1538f3aef538/Ebook\%20 Metodologia\%20do\%20Trabalho\%20Cientifico.pdf>. Acesso em: 18 jan. 2017.

TYPOGRAPHY primer. 2000. Disponível em: <http://info.ils.indiana. edu/ katy/S637-S11/Adobe-type-primer.pdf>. Acesso em: 8 maio 2018. 